\title{
The added value of dynamical downscaling
}

\author{
$\underline{\text { J. Katzfey }}^{\text {a }}$, M. Chattopadhyay ${ }^{\text {a }}$, J.L. McGregor ${ }^{\text {a }}$, K. Nguyen ${ }^{\text {, }}$, and M. Thatcher ${ }^{\text {a }}$ \\ ${ }^{a}$ CSIRO Marine and Atmospheric Research, PMB 1, Aspendale, Victoria 3195 Australia \\ Email:jack.katzfey@csiro.au
}

\begin{abstract}
Recently two major projects have been completed that used dynamical downscaling for providing detailed climate change projections. The first, the Climate Futures for Tasmania (CFT) project, involved running the Conformal Cubic Atmospheric Model (CCAM) at $60 \mathrm{~km}$ resolution over Tasmania using a variable-resolution global grid and then further downscaling to $14 \mathrm{~km}$ resolution over the same area. Bias-corrected sea surface temperatures from six different Global Climate Models (GCMs) were used as host model information to drive CCAM, using two IPCC AR4 SRES emissions scenarios (A2 and B1). The second project, the Pacific Climate Change Science Program (PCCSP), involved running CCAM globally at (quasi) uniform $60 \mathrm{~km}$ resolution and then further downscaling to $8 \mathrm{~km}$ resolution for seven Pacific Island regions. Again, CCAM is driven by bias-corrected sea surface temperatures from the same six GCMs for only the A2 emissions scenario. Since these two projects are from very different climate regions (CFT is a mid-latitude case while the PCCSP is over the tropical Pacific Ocean), they provide useful and interesting cases to test the value of high-resolution downscaling.
\end{abstract}

Assessing uncertainty and adding value through downscaling is demonstrated in both projects by decreased biases in the simulation of the current climate, providing a more detailed, physically derived, process-based projection and providing an ensemble of runs. The current climate is more realistically captured at the higher resolutions when compared to the gridded observations. The climate change signal is significantly altered by the higher resolution and more realistically resolved topography. In the higher resolution simulations, there is enhanced rainfall when the increased amount of available water vapour in the projected future climate is lifted over the mountain ranges, and lee-mountain effects are better resolved.

Results show that the bias-correction of the sea surface temperatures and increased resolution improves the representation of the current climate. The impact of the local topography can significantly modulate the climate change signal coming from the host GCMs. In summary, great care must be taken when assessing local patterns of climate change, especially in regions of significant, complex orography. When making impact assessments for such regions, results from downscaled climate change projections which include the effect of topography should be used.

Keywords: $\quad$ Dynamical downscaling, regional climate change, ensemble predictions 


\section{INTRODUCTION}

Dynamical downscaling using regional climate models provides a methodology for obtaining more detailed regional-to-local scale climate change information, in order to better assess the impact of anthropogenic climate change and to develop appropriate adaptation measures. As regional climate models are usually not fully coupled global atmosphere-ocean models, they rely on information from coarser resolution global climate models (GCMs, sometimes called host GCMs). Due to computational cost, the GCMs are run at a relatively coarse resolution (typically $100-200 \mathrm{~km}$ in recent IPCC AR4 simulations). The downscaling uses information from the GCMs and dynamically simulates the regional climate at higher resolution.

There are three ways that regional climate modelling can potentially decrease uncertainty and add value to climate projections: 1) by decreasing the simulation biases of the current climate, 2) increasing the amount of spatial and temporal information, and 3) providing a more realistic representation of the spread of future regional climate projections. Most regional climate modelling addresses the second point - that is, the regional model is run at higher resolution nested within a GCM in order to provide a more detailed depiction of the regional climate. Changing the large-scale biases of the GCM is usually not possible, since these regional models are driven by lateral boundary conditions from the host GCM. Ensemble regional climate projections can help provide information on the spread or uncertainty of the future climate.

This paper describes a few ways in which downscaling can decrease uncertainty and add value, both through correcting some of the biases in GCMs and incorporating additional information through better resolution of the land surface and atmospheric dynamics. The results presented here are qualitative; a more quantitative assessment of added value, such as proposed in Kanamitsu and DeHaan (2011) or in Frauke (2011), is a subject of future research. The next Section describes the tools and methodology used in this study. Then, examples of a mid-latitude (Climate Futures for Tasmania (CFT), Corney et al., 2010) and a tropical case (Pacific Climate Change Science Programme, PCCSP) are presented. The results are summarised and discussed in the final section.

\section{METHODOLOGY}

\subsection{Choice of emissions scenario}

Since it is highly likely that anthropogenic pollutants are responsible for most recent global warming (IPCC 2007), it follows that the extent of anticipated climate change is dependent on the amount of future greenhouse gas emissions. A commonly used and accepted set of greenhouse gas emission scenarios, known as the Special Report on Emissions Scenarios (SRES), comes from IPCC AR4 (2007). The scenarios primarily used here are from the high-emission A2 scenario because current emission levels are at, or already above, those specified for this scenario (Raupach et al., 2010) and therefore this appears to be the most realistic choice. For the CFT project, we also downscaled for the low-end, B1, scenario.

\subsection{Choice of coupled global climate models}

Although there are 23 GCMs available from World Climate Research Programme (WCRP) Coupled Model Intercomparison Project phase 3 multi-model dataset archive (CMIP3, Meehl et al., 2007), we have chosen to downscale only six GCMs, so that the dynamical downscaling could be completed with a practical amount of computing resources. The six GCMs represent some of the uncertainty in the rate of global warming due to their different dynamical formulations and physical parameterizations.

The six models chosen for this study were based on the study of Smith and Chandler (2009), where the ability of the models to simulate present-day means and variability over Australia was assessed. The six GCMs that were chosen for this study are listed in Table 1. By concentrating our efforts on these six models in an ensemble projection, we aim to assess some of uncertainty associated with downscaling all 23 IPCC runs, while also maximising the value of our model results by choosing models with realistic inter-annual variability. A common feature of these six GCMs is that they tend to have better simulations of El Niño than some of the others. Details of the model configurations and associated references can be found at http://wwwpcmdi.llnl.gov/ipcc/model_documentation/ipcc_model_documentation.php. The model data used here were obtained from the CMIP3 data archive for PCMDI at Lawrence Livermore National Laboratory (http://www-pemdi.llnl.gov/). 
Table 1: Six GCMs used to downscale, along with country of origin and approximate resolution.

\begin{tabular}{|c|c|c|}
\hline GCM & Country of origin & $\begin{array}{c}\text { Approximate horizontal } \\
\text { resolution (km) }\end{array}$ \\
\hline ECHAM5/MPI & Germany & 169 \\
\hline GFDL_CM2.0 & USA & 198 \\
\hline GFDL_CM2.1 & USA & 198 \\
\hline CSIRO Mk3.5 & Australia & 169 \\
\hline UKMO_HadCM3 & United Kingdom & 273 \\
\hline MIROC_Medres & Japan & 248 \\
\hline
\end{tabular}

\subsection{Conformal Cubic Atmospheric Model}

CSIRO Marine and Atmospheric Research have been undertaking regional climate modelling for nearly two decades. For the past decade the Conformal Cubic Atmospheric Model (CCAM) has been the mainstay of CSIRO dynamical downscaling (McGregor, 1996, 2005a, 2005b; McGregor and Dix, 2001, 2008). CCAM is a full atmospheric GCM formulated on the conformal-cubic grid. CCAM includes a quite comprehensive set of physical parameterizations for climate modelling, including the GFDL parameterizations for long-wave and short-wave radiation (Schwarzkopf and Fels, 1991; Lacis and Hansen, 1974), with interactive cloud distributions determined by the liquid and ice-water scheme of Rotstayn (1997). The model employs a stability-dependent boundary layer scheme based on Monin-Obukhov similarity theory (McGregor et al., 1993). A canopy scheme is included, as described by Kowalczyk et al. (1994), having six layers for soil temperatures, six layers for soil moisture (solving Richard's equation) and three layers for snow. The cumulus convection scheme uses mass-flux closure, as described by McGregor (2003), and includes downdrafts, entrainment and detrainment. CCAM may be employed in quasi-uniform mode or in stretched mode by utilizing the Schmidt (1977) transformation. The model can also downscale to higher resolutions using a scale-selective digital filter (Thatcher and McGregor, 2009) to force the courser resolution information into the finer resolution simulation. Simulations presented here were completed with 18 vertical levels.

All simulations used interpolated monthly SSTs and sea-ice cover as provided by the GCMs. Since the GCMs tend to have biases in SSTs relative to observed climatologies (Reynolds, 1988), the next step is to correct these SST biases. The monthly climatologies of the GCM SSTs are first determined for the current climate (1961-2000). This is done by computing the GCM SST bias relative to the Reynolds-based (1988) SST climatology for each month. Then, the monthly bias is subtracted from each monthly GCM SST field before using it in the downscaled simulations. Using this technique, the climatology of the SSTs in the downscaled simulation for the current climate is the same as the observed climatology. Since the monthly bias correction is unchanged throughout the run, both the interannual variability and climate change signal of the GCM SSTs are also not altered. See Katzfey et al. (2009) for more discussion of the bias correction method.

\section{DECREASING UNCERTAINTY AND ADDING VALUE THROUGH DOWNSCALING}

Uncertainty of climate projections comes from the emission scenario employed, model sensitivity, model errors, downscaling approaches, downscaled model errors, and techniques used for impact assessments. Jones (2000) discusses the uncertainty explosion as one goes from emissions scenarios through to impact assessments. However, Jones (2000) does not address the possibility of reducing uncertainty through downscaling. These potential reductions in uncertainty are discussed next, with examples given.

When downscaling, there is no apparent way to decrease the uncertainty associated with emission scenarios. These are based upon economic, social and technological assumptions of future development. The only way to address this uncertainty is through use of GCMs driven by multiple scenarios. An example of the impact of using different scenarios can be seen in the annual and state-wide averaged maximum temperature for Tasmania, downscaled to $14 \mathrm{~km}$ from six different downscaled GCMs with both the A2 and B1 SRES scenarios (Figure 1). At least for this region, the differences between the two scenarios do not become apparent until after about 2050 . 


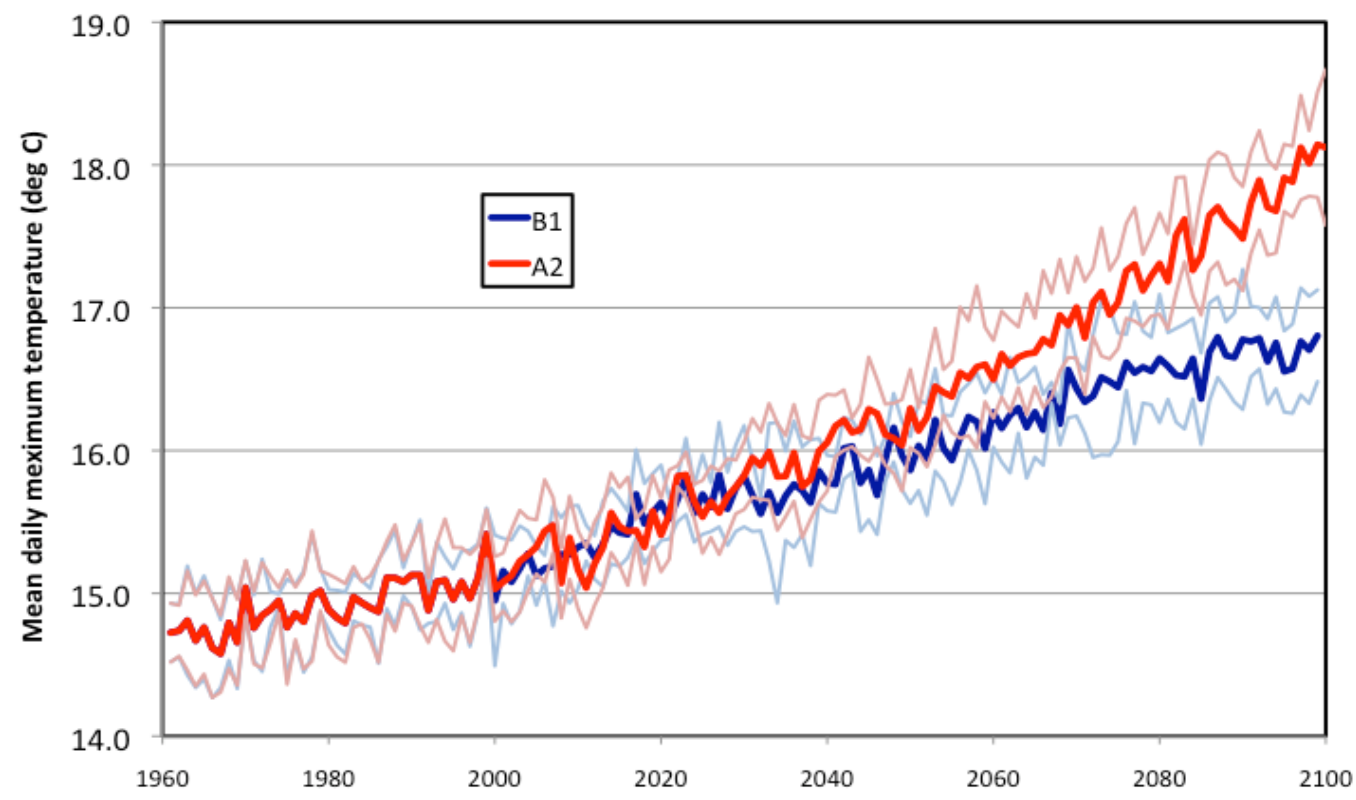

Figure 1: Tasmania-wide, yearly-averaged daily maximum temperatures from $14 \mathrm{~km}$ CCAM downscaled simulations using six GCMs for A2 (red lines) and B1 (blue lines) SRES scenarios. Thick line is ensemble mean while thin lines are standard deviation of the six members. (Adapted from Grose et al., 2010).

Because a significant portion of the globe is covered by oceans, correction of the SSTs can help reduce some of the model errors and biases and decrease the large uncertainty related to these biases. The positive effect of this adjustment is summarised in Table 2. These are results from the PCCSP project over the Pacific, showing the impact of the bias correction on the pattern of surface air temperature and rainfall. For temperature, all but the ensemble-mean temperature are improved in the downscaled simulations. The GCMs have larger errors, as shown in the MAE statistic, but the ensemble-mean bias is less due to counteracting errors among members of the ensemble. The larger errors in the GCMs of potentially opposite sign can lead to greater cancellation (for the current climate) than when using one RCM, where the bias correction will make all current climate simulations very similar, with little scope for cancellation of errors. For rainfall, the bias is again smaller for the GCMs, but with larger MAE, there are again counteracting errors for the ensemble mean. The correlation over time is slightly better in the GCMs, indicating that the GCMs capture the seasonality slightly better, while the spatial correlation is better in the downscaled runs.

Table 2: Combined statistics for GCM ensemble and CCAM 60km ensemble simulations for surface air temperature $\left({ }^{\circ} \mathrm{C}\right)$ against ERA-40, NCEP2 and JRA25 analyses (top) and rainfall (mm/day) against CMAP and GPCP (bottom). Bold values show better results for multi-model means (top). For comparison, statistics for the multi-model means of the $23 \mathrm{GCM}$ ensemble are also given. Domain is $125^{\circ} \mathrm{E}$ to $150^{\circ} \mathrm{W}$ and $25^{\circ} \mathrm{S}$ to $20^{\circ} \mathrm{N}$, time period 1980-1999. All statistics are averaged among members of the ensemble. The statistics shown are the Bias: mean error, MAE: mean absolute error, $\operatorname{Corr}(\mathrm{t})$ : correlation over time, and $\operatorname{Corr}(\mathrm{xy})$ : spatial correlation.

\begin{tabular}{|l|l|l|l|l|}
\hline & Bias & MAE & Corr.(t) & Corr.(xy) \\
\hline Surface air temperature & & & & \\
\hline Average (23 GCMs) & -0.76 & 1.02 & 0.74 & 0.89 \\
\hline 6 GCM Average & $\mathbf{- 0 . 4 0}$ & 1.03 & 0.77 & 0.90 \\
\hline 6 Downscaled CCAM average & 0.50 & $\mathbf{0 . 5 5}$ & $\mathbf{0 . 9 3}$ & $\mathbf{0 . 9 7}$ \\
\hline Rainfall & & & & \\
\hline Average (all 23 GCM) & 0.39 & 1.77 & 0.55 & 0.63 \\
\hline 6 GCM Average & $\mathbf{0 . 6 2}$ & 1.88 & $\mathbf{0 . 5 9}$ & 0.68 \\
\hline 6 Downscaled average & 1.00 & $\mathbf{1 . 3 3}$ & 0.51 & $\mathbf{0 . 7 6}$ \\
\hline
\end{tabular}


A key feature of the bias correction is that it needs to be made over the whole globe in order to affect the large-scale flow field of the region. Use of a stretched-grid model (either stretched as in the CFT project, see Corney et al.,2010, or unstretched as in the PCCSP project, where the globe was at approximately $60 \mathrm{~km}$ resolution everywhere), allows the bias correction to affect and improve the large-scale flows (not shown). With limited-area models, the lateral boundary conditions specified from the GCM would still have those large-scale biases. Lateral boundary conditions in limited-area models can also introduce additional biases through the discrete jump in resolution, the required interpolation in space and time and through issues related to differences between the physics of the host GCM and the regional model.

The use of ensembles of downscaled simulations also provides some indication of the uncertainty. Although the computational cost of downscaling typically prevents use of all GCMs available, a subset of GCMs will provide some measure of the spread of future climate projections. In combination with the bias correction, the downscaled runs will have a more realistic current climate which the future scenario will perturb. The spread of the future projections typically will be less than in the GCMs, mainly because the current climate will be more similar (and more realistic) than the GCMs. An example of the variation among the six members of the $14 \mathrm{~km}$ downscaled simulations for the CFT project of projected annual rainfall changes over Tasmania with the A2 SRES scenario is shown in Figure 2. Due to differing patterns and amounts of SST warming in the host GCMs, a range of possible rainfall changes is projected. The most consistent pattern of change is the decrease over the central regions of Tasmania. There is also a tendency for decreases in northwestern regions of the state. These changes, especially on the seasonal level (not shown) are related to circulation changes driven by the SST changes and the interaction of these changes with the orography. The high-resolution orography significantly modifies the local response of the climate change signal in a physically based response. This provides a clear demonstration of the value adding of high-resolution downscaling.

$$
\text { GFDL } 2.0
$$

0

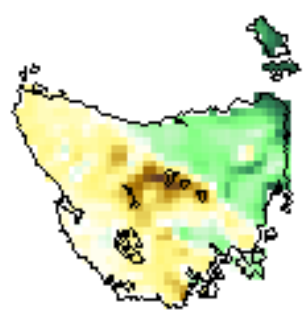

ECHAM 5

0

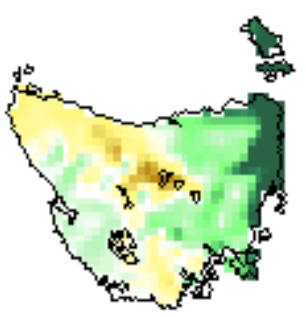

$\operatorname{CSIRO~} 3.5$

0

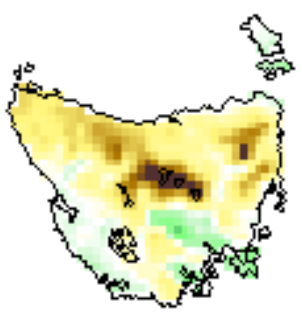

GFDL 2.1

$\{3$

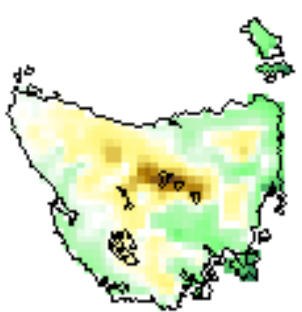

MIROC Medres

0

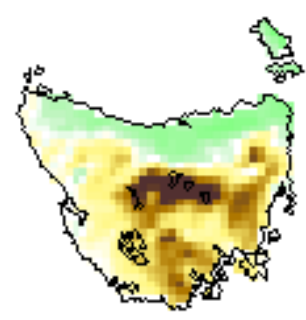

HadCM 3

0

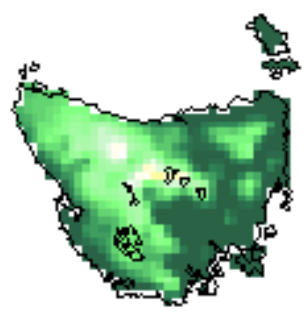

Figure 2: Change in annual rainfall (mm/day) from 1985 to 2080 for Tasmania from six $14 \mathrm{~km} \mathrm{CCAM}$ downscaled simulations for Tasmania for SRES A2 scenario. 


\section{CONCLUSIONS AND RECOMMENDATIONS}

In this paper, a summary is given of dynamical downscaling recently completed at CMAR, showing that it is possible to add value to climate change projections and also to reduce the uncertainty.

Use of a stretched-grid model eliminates some issues associated with limited-area models. There are no lateral boundary conditions to introduce errors, as in limited-area models, and two-way interaction is permitted between the regions of high resolution and lower resolution. Since CCAM is a global model, it allows global bias correction of SSTs, which improves the simulation of the current climate and thereby should provide a more realistic starting point for the effects of climate change. A scale-selective filter allows the model to be nested within itself to downscale to even higher resolution, without the domain size and placement issues which are typical of limited-area models.

Key results are:

1) Use of a stretched-grid model allows interaction between regional and larger scales, as well as eliminating issues with lateral boundary conditions, domain size and location; such issues create difficulties for limited-area regional climate models.

2) Use of bias-corrected sea surface temperatures reduces errors in the representation of the current climate and thereby reduces some of the uncertainty in future climate projections.

3) Downscaling an ensemble of GCMs in order to assess the possible range of projections improves the projections.

4) Running the downscaling model at high resolution better represents the surface forcing (orography, land use, coastlines) and more realistically simulates weather phenomena.

Since the downscaling approach relies upon the ocean temperature projections coming from the host GCMs, improvements in global models will lead to improved projections from regional climate models. The regional model can be further improved through more realistic representation of the land surface and incorporation of some variation of the ocean surface temperature through inclusion of a mixed-layer ocean or even coupling to a regional ocean model. Additional issues that need to be addressed are the relationship of the RCM projections to those of the host GCM.

\section{ACKNOWLEDGMENTS}

Part of this work was supported by the Australian government's Cooperative Research Centres Program through the Antarctic Climate and Ecosystems Cooperative Research Centre (ACE CRC). Climate Futures for Tasmania was possible with support through funding and research of a consortium of state and national partners. Part of this work is also supported by the Pacific Climate Change Science Program. We acknowledge the six GCM modelling groups, the Program for Climate Model Diagnosis and Intercomparison (PCMDI) and the WCRP Working Group on Coupled Modelling (WGCM) for making available the WCRP CMIP3 multi-model dataset. Support of this dataset is provided by the Office of Science, U.S. Department of Energy.

\section{REFERENCES}

Corney S.P., J.J. Katzfey, J.L. McGregor, M.R. Grose, J.C. Bennett, C.J. White, G.K. Holz, S.M. Gaynor, and N.L. Bindoff (2010). Climate Futures for Tasmania: climate modelling technical report, Antarctic Climate and Ecosystems Cooperative Research Centre, Hobart.

Dommenget, D. (2009). The ocean's role in continental climate variability and change. Journal of Climate, 22, 4939-4952.

Grose, M.R., I. Barnes-Keoghan, S.P. Corney, C.J. White, G.K. Holz, J.C. Bennett, S.M.Gaynor and N.L. Bindoff (2010). Climate Futures for Tasmania: general climate technical report, Antarctic Climate and Ecosystems Cooperative Research Centre, Hobart, Tasmania.

Frauke F., B. Rockel, H. von Storch, J. Winterfeldt, and M. Zahn (2011). Regional climate models add value to global model data. Bulletin of the American Meteorological Society, e-View doi: 10.1175/2011BAMS3061.1.

Jones, R.N. (2000). Managing uncertainty in climate change projections: Issues for impact assessment. Climatic Change, 45(3-4), 403-419.

Kanamitsu, M. and L. DeHaan (2011). The added value index: A new metric to quantify the added value of regional models. Journal of Geophysical Research, 116, D11106, doi:10.1029/2011JD015597. 
Kanamitsu, M., K.Y. Yoshimura, B. Yhang, and S.Y. Hong (2010). Errors of interannual variability and trend in dynamical downscaling of reanalysis. Journal of Geophysical Research, 115, D17115, doi:10.1029/2009JD013511.

Katzfey J.J., J.L. McGregor, K.C. Nguyen and M. Thatcher (2009). Dynamical downscaling techniques: Impacts on regional climate change signals. Proceedings, World IMACS/MODSIM Congress, Cairns.

Kowalczyk, E., J.R. Garratt, and P.B Krummel. (1994). Implementation of a soil-canopy scheme into the CSIRO GCM - regional aspects of the model response. CSIRO Div. Atmospheric Research Tech Paper No. 32, 59 pp.

Lacis, A. and J. Hansen (1974). A parameterization of the absorption of solar radiation in the Earth's atmosphere. Journal of Atmospheric Science, 31, 118-133.

McGregor, J.L., H.B. Gordon, I.G. Watterson, M.R. Dix, and L.D. Rotstayn (1993). The CSIRO 9-level atmospheric general circulation model. CSIRO Div. Atmospheric Research Tech. Paper No. 26, 89 pp.

McGregor, J.L. (2003). A new convection scheme using a simple closure. In "Current issues in the parameterization of convection", BMRC Research Report 93, 33-36.

McGregor, J.L. (2005). C-CAM: Geometric aspects and dynamical formulation [electronic publication]. CSIRO Atmospheric Research Tech. Paper No. 70, 43 pp.

McGregor, J.L., and M.R. Dix (2001). The CSIRO conformal-cubic atmospheric GCM. In IUTAM Symposium on Advances in Mathematical Modelling of Atmosphere and Ocean Dynamics, P. F. Hodnett (ed.), Kluwer, Dordrecht, 197-202.

McGregor, J.L., and M.R. Dix (2008). An updated description of the Conformal-Cubic Atmospheric Model. In High Resolution Simulation of the Atmosphere and Ocean, K. Hamilton and W. Ohfuchi (eds.), Springer, 51-76.

Reynolds, R.W. (1988). A real-time global sea surface temperature analysis. Journal of Climate, 1, 75-86.

Rockel, B., C.L. Castro, R.A. Pielke, H. von Storch, and G. Leoncini (2008). Dynamical downscaling: Assessment of model system dependent retained and added variability for two different regional climate models. Journal of Geophysical Research, 113, D21107, doi:10.1029/2007JD009461.

Rotstayn, L.D. (1997). A physically based scheme for the treatment of stratiform clouds and precipitation in large-scale models. I: Description and evaluation of the microphysical processes. Quarterly Journal of the Royal Meteorological Society, 123, 1227-1282.

Schwarzkopf, M.D. and S.B. Fels (1991). The simplified exchange method revisited: An accurate, rapid method for computation of infrared cooling rates and fluxes. Journal of Geophysical Research, 96, 90759096.

Smith I., and E. Chandler (2010). Refining rainfall projections for the Murray Darling Basin of south-east Australia - the effect of sampling model results based on performance. Climate Change, DOI 10.1007/s10584-009-9757-1.

Thatcher M. and J.L. McGregor (2009).Using a scale-selective filter for dynamical downscaling with the conformal cubic atmospheric model. Monthly Weather Review, 137, 1742-1752. 